\title{
Wages, productivity, and work intensity in the Great Depression
}

\author{
Julia Darby* \\ University of Strathclyde \\ (julia.darby@strath.ac.uk)
}

\author{
Robert A. Hart \\ University of Stirling \\ (r.a.hart@stir.ac.uk)
}

(April, 2007)

\begin{abstract}
:
We show that U.S. manufacturing wages during the Great Depression were importantly determined by forces on firms' intensive margins. Short-run changes in work intensity and the longer-term influence of potential productivity combined to influence real wage growth. By contrast, the external effects of unemployment and replacement rates had much less impact. Empirical work is undertaken against the background of a simple efficient bargaining model that embraces earnings, employment, hours of work and work intensity.
\end{abstract}

JEL Classification: J24, J31, N62

Acknowledgements: We are grateful to two anonymous referess, Dan Anderberg, George Johnson, and Campbell Leith for helpful comments. We also thank Ben Bernanke for access to the data used in this project.

* Corresponding author: Department of Economics, University of Strathclyde, 130 Rottenrow, Glasgow, G4 0GE, Scotland, U.K. 


\section{Introduction}

One of the most interesting puzzles concerning the behavior of real wages over the business cycle is their failure to adjust downwards in the face of exceptional increases in unemployment during the Great Depression. In fact, evidence from the United States supports the view that real wages were not merely unresponsive to unemployment changes at this time but apparently positively related (Bernanke and Powell, 1986). One potential reason is that indicators of external market conditions, such as the rate of unemployment, only partially represent the key forces acting on the wage. Firms’ intensive margins matter. Theories of rent sharing, efficiency wages and implicit contracts recognize the importance of within-company implicit or explicit agreements that serve to shield workers, at least in part, against excessive fluctuations in per period earnings stemming from external market forces.

Bernanke (1986) provides perhaps the best known attempt to tackle the puzzle of counter-cyclical U.S. wages in the 1930s. This work brings the intensive margin prominently into play by emphasising the role of hours of work. Weekly hours fell in response to the severe cyclical downturn. ${ }^{1}$ However, if hours had been allowed to fall by the fully required amount, any value to workers of increased leisure would have been far more than offset by their loss of consumption due to reduced weekly earnings. Firms were constrained by workers' reservation utilities from cutting earnings to the same extent as the hours reductions with the result that average hourly earnings could remain constant, or even rise, as labor demand fell. Bernanke tests this story with industry-level earnings equations in which nominal weekly earnings are expected to relate positively to

\footnotetext{
${ }^{1}$ There were also strong hours' effects in Britain at this time with important implications for earnings adjustments. See Hart (2001) for a discussion of the British Engineering Industry.
} 
weekly hours and to industry employment as well as positively to workers’ reservation utilities as captured by a group of variables that include union power and the cost of living.

In Bernanke's story, the firm cuts working time in response to a demand fall but, in order to ensure that employees turn up for work, it may feel constrained not to cut earnings to the same extent. This does not rule out the possibility, assuming diminishing returns, that hourly productivity remained fairly stable. We also emphasise the importance of the intensive margin. However, we concentrate on the fact that hourly labor productivity in manufacturing fell considerably during the period 1929 to $1933^{2}$. This meant, effectively, that work intensity reduced as represented by an increased excess of total paid-for to actual effective hours worked. We are concerned to find out whether this change in work intensity directly impacted on the wage.

Technological and organizational constraints, scheduling requirements of suppliers and customers, and working time custom and practice may have variously prevented full downward hours adjustment to the severe fall in product demand experienced during the early 1930s. The implied reductions in hourly work intensity may have resulted from, among other possibilities, reductions in the speed of production throughput or in the number of required job tasks per unit of time or even through increases in the length of daily rest periods. In effect, changes in work intensity offered a means, alongside changes in earnings and employment, of adjusting to the new trading climate. In our set-up, management and workers seek to reach agreement on the desired

2 Cole and Ohanian, (1999, Table 6) show that labor productivity - measured in terms of output per hour fell in 1932/33 to about 12 percent below its 1929 detrended level. Thereafter it rose quite speedily, returning to trend in 1936. Ohanian (2002) discusses a range of factors influencing productive efficiency that may have contributed to these observed movements, and we return to the implications of his suggestions in our concluding section. 
mix of earnings levels, labor inputs (workers and hours), and the degree of work intensity. There is some precedent for adopting this modelling approach. In a firm-union bargaining context, Johnson (1990) argues strongly that work intensity is an issue on collective bargaining agendas.

Essentially, we follow an important paper by Taylor (1970) in this journal by proxying work intensity within an empirical wage specification that also embraces the unemployment rate. The latter variable enters our model via its influence on compensation in workers' alternative employment. Following Darby et al. (2001), our arguments are formalized within a simple efficient bargaining framework in which earnings, employment, hours and work, and work intensity are choice variables. We undertake empirical tests on United States manufacturing using a data set originally constructed and analysed by Bernanke and Parkinson (1991).

\section{An efficient bargain}

Ignoring the capital stock ${ }^{3}$, the firm's production function is given by

(1) $Q=F(\theta, h, N)$

with $F^{\prime}>0, F^{\prime \prime}<0$ and where $Q$ is output, $\theta$ is average work intensity, $h$ is average paidfor weekly hours, $N$ is the size of the workforce. Work intensity is an index, with $0 \leq \theta$ $\leq 1$. Essentially, including $\theta$ in the production function serves to convert paid-for into effective hours worked.

Also ignoring fixed costs of employment for simplicity ${ }^{4}$, profit is expressed

\footnotetext{
3 Primarily because the inclusion of capital and its user cost changes nothing of substance in our main concern, the wage determination process.
} 


$$
\pi=p F(\theta, h, N)-y N
$$

where $p$ is the product price, $y$ is average weekly earnings. Specifically, $y=w h$ where $w$ is the average hourly wage rate.

For the representative worker, positive utility derives from wage earnings, while disutility stems from greater work intensity over the workweek and from the loss of leisure. Assuming fixed disutilities of work intensity and hours, utility is expressed (3) $u=u\left(y-\gamma \theta h-\beta h-y^{*}\right)$

where $\mathrm{y}^{*}$ is weekly compensation in alternative employment and $\beta$ and $\gamma$ are constants. ${ }^{5}$ Assuming that the worker is risk neutrality, or $\mathrm{u}^{\prime}>0, \mathrm{u}^{\prime \prime}=0$ and aggregating over the whole workforce, $N$, gives workers' utility as

(4) $U=N\left(y-\gamma \theta h-\beta h-y^{*}\right)$.

The generalised Nash bargain (Svejnar, 1986) is the solution to the problem

$$
\max _{\mathrm{y}, \theta, \mathrm{h}, \mathrm{N}} J=\pi^{1-\alpha} \mathrm{U}^{\alpha}
$$

where $\alpha$ represents workers' relative bargaining power (or 'strength'), with $\alpha \in\{0,1\}$.

From the first-order conditions, we obtain

(6) $\frac{\mathrm{pF}_{\mathrm{h}}}{\mathrm{N}}=\beta+\gamma \theta$

\footnotetext{
${ }^{4}$ Thus, we discount the possibility that the firm may negotiate the level of worker quality and associated training costs. For extensions along these lines see Hart and Moutos (1995).

${ }^{5}$ Slightly more explicitly, we can write work-related utility as u $\{\mathrm{y}-\delta \phi \mathrm{h}-\beta(1-\theta) \mathrm{h}\}$ where $\delta$ and $\beta$ are constants. This divides the workweek into effective hours worked, $A$ h, and additional hours worked, $(1$ $\theta)$ h. Disutility from the first part stems from the degree of work intensity. The second part represents nonwork activity but still adds to disutility because workplace attendance is required. In general, we might expect that $\delta>\beta$. In the equivalent expression in (3) $\gamma=\delta$ - $\beta$.
} 
or the average marginal product of hours is equal to the cost of employing an extra hour. This cost is equal to the marginal disutility of hours worked. Similarly, we obtain

(7) $\frac{\mathrm{pF}_{\theta}}{\mathrm{N}}=\gamma \mathrm{h}$

i.e. the average marginal product and marginal disutilities of effort are equated.

Optimal employment is achieved by equating marginal value product to a worker's opportunity cost of work, or

$$
\mathrm{pF}_{\mathrm{N}}=\gamma \theta \mathrm{h}+\beta \mathrm{h}+\mathrm{y}^{*} \text {. }
$$

Of key importance to present developments, the equilibrium wage ${ }^{6}$ is given by

(9) $y=\alpha \frac{\mathrm{pQ}}{\mathrm{N}}+(1-\alpha) \mathrm{pF}_{\mathrm{N}}$

If the workforce has no bargaining power, or $\alpha=0$, the firm is on its demand curve, with marginal product equal to the marginal cost of an additional worker. At the other extreme, $\alpha=1$, the firm receives zero profit.

Combining (8) and (9) produces

$$
\mathrm{y}=\alpha \frac{\mathrm{pQ}}{\mathrm{N}}+(1-\alpha)\left(\gamma \theta \mathrm{h}+\beta \mathrm{h}+\mathrm{y}^{*}\right)
$$

and this can be written in hourly terms as

$$
\mathrm{w}=\varphi_{0}+\varphi_{1} \frac{\mathrm{pQ}}{\mathrm{Nh}}+\varphi_{2} \theta+\varphi_{3} \mathrm{w}^{*}
$$

where $\mathrm{w}^{*}$ is the outside hourly wage $\left(=\mathrm{y}^{*} / \mathrm{h}\right)^{7}$, and $\varphi^{\prime}$ s are parameters. This is our core wage equation: the wage rate is dependent on hourly productivity, hourly work intensity and the outside hourly wage.

\footnotetext{
${ }^{6}$ The first-order condition, $\mathrm{J}_{\mathrm{N}}=0$ to the problem in (5) is given by $\pi^{-\alpha} \mathrm{U}^{\alpha}(1-\alpha)(\mathrm{pF}-\mathrm{y})+\pi^{1-\alpha} \mathrm{U}^{\alpha-1} \alpha \mathrm{U} / \mathrm{N}=0$ Multiplying through this expression by $\pi^{\alpha} \mathrm{U}^{-\alpha}$ and re-arranging produces equation (9).
} 
As will be seen in the following Section and beyond, our approach to estimation allows us to distinguish between long-run and short-run influences on the wage. With this in mind, and without detracting significantly from our basic story, we believe that there are advantages in extending our interpretation of the roles of productivity and work intensity somewhat beyond the confines of our simple model. Rather than seek to reach agreement over current productive performance, we assume that the parties link the wage to potential productivity. ${ }^{8}$ We can think of potential productivity as the maximum expected hourly output when all factors are fully utilised. Corresponding wage increases would depend on long term technical, organizational, and human capital improvements. The work intensity term then serves to account for periods when actual productivity falls short of potential productivity and the parties recognize shorter term wage adjustments may need to accommodate this.

An immediate gain from these interpretations is that we can take advantage of the simple intensity expression of Fair (1985). This is given by

$$
\theta=\frac{\phi}{\phi^{*}}
$$

where $\phi=\mathrm{Q} / \mathrm{Nh}$ is actual hourly productivity - or output per paid-for worker hours - and $\phi^{*}$ is potential hourly productivity. Our measure of $\phi^{*}$ replaces the hourly productivity term in (11). The outcome $\phi=\phi^{*}$ implies $\theta=1$ or the firm is operating at maximum work intensity. In this case, actual and paid-for hours of work coincide. This is assumed to occur at the cyclical peak points of $\phi\left(=\phi^{*}\right)$. If the firm were to maintain the path

\footnotetext{
${ }^{7}$ The outside wage is expressed in terms of 'inside' weekly hours. It seems not unreasonable to assume that, in comparing inside and outside hourly earnings, workers will deflate by hours currently experienced.

${ }^{8}$ Current productivity is especially relevant to wage determination that involves incentive pay (such as piece rates) in which output and the quality of output are perpetually monitored.
} 
satisfying $\phi=\phi^{*}$, then only long-term capital, training, and organizational changes would affect the wage. If $\phi<\phi^{*}$, work intensity is below its maximum (ie. actual productivity falls short of potential productivity) and the parties may agree to an offsetting wage reduction.

The value of the expected outside union wage, $\mathrm{w}^{*}$ in (11), results from two components weighted by their probability of their occurrence. First, the value of the expected wage obtained if the worker is re-employed. Second, the replacement rate received if the worker is unemployed. The probability of gaining employment should relate negatively to the rate of unemployment. For simplicity, we capture the fallback wage by the linear approximation

$$
\mathrm{w}^{*}=\overline{\mathrm{w}}+\eta_{1} \mathrm{u}+\eta_{2} \mathrm{r}
$$

where $\overline{\mathrm{w}}$ is the average wage in the economy, $\mathrm{u}$ is unemployment, $\mathrm{r}$ is the replacement ratio and $\eta$ 's are parameters. Based on the data provided by Darby (1976), our replacement ratio is represented by the relative wage of an emergency worker, funded through various New Deal programmes.

\section{Empirical wage specification and data}

Our empirical wage equation contains three main features. First, it incorporates the potential productivity, work intensity, unemployment and replacement ratio variables arising from the foregoing discussion. Second, following Bernanke (1986), it includes two variables to capture the level of government relief and the strength of the labor movement respectively. As detailed in the Data Appendix, Strike is intended to capture the resurgence of the labor movement after the New Deal and NRA is intended to capture any wage impact of the National Recovery Act. Third, it embraces data determined 
dynamic influences through separate nominal wage and price inflation terms in order to capture short term nominal inertia which can reflect generalized dynamic adjustment, including aggregation effects generated by staggered contracting.

For each industry, the complete specification is given by

$$
\begin{aligned}
& \Delta \ln W_{\mathrm{t}}=b_{0}+\Sigma b_{1 \mathrm{i}} \Delta \ln W_{\mathrm{t}-\mathrm{i}}+\Sigma b_{2 \mathrm{i}} \Delta \ln P_{\mathrm{t}-\mathrm{i}}+\Sigma b_{3 \mathrm{i}} \Delta \ln \theta_{\mathrm{t}-\mathrm{i}}+b_{4 \mathrm{i}} \Sigma \Delta \ln u_{\mathrm{t}-\mathrm{i}} \\
& +b_{5} \ln (W / P)_{\mathrm{t}-1}+b_{6} \ln \phi_{\mathrm{t}-1}^{*}+b_{7} \ln \theta_{\mathrm{t}-1}+b_{8} \ln u_{\mathrm{t}-2} \\
& \quad+b_{8} \ln r_{\mathrm{t}}+b_{9} \text { Strike }_{\mathrm{t}}+b_{10} N R A_{\mathrm{t}}+\text { seasonals }+v_{\mathrm{t}}
\end{aligned}
$$

where $W$ is the nominal wage; $P$ is the consumers' expenditure deflator; $\theta$ is work intensity, $u$ is the measured unemployment rate and $\phi^{*}$ is potential productivity and $v$ is an error term. Nominal wages, potential productivity and work intensity are measured on an industry specific basis, all other variables are whole economy measures. Data were obtained from Bernanke and Parkinson (1991), and we present estimates for 7 of their 10 industries. These are Leather, Lumber, Petrol, Paper and Pulp, Rubber, Steel, and Textiles $^{9}$. The original data are monthly. However, we follow Bernanke and Parkinson’s approach of temporally aggregating monthly to quarterly observations in order to reduce the effects of possible measurement error or temporal misalignments in data from different primary sources.

\footnotetext{
${ }^{9}$ We omit two industries that were included in Bernanke and Parkinson's dataset - Non Ferrous Metals and Sand, and Clay and Glass - because the data were available for a significantly shorter sample period. We also excluded Autos. Data for automobile production showed a pronounced cyclical pattern, which evolved over time and probably stemmed from the release of new models on an annual basis, a practice that continued throughout the Depression. We attempted to seasonally adjust this production data prior to calculating productivity, potential productivity and work intensity. However, our resulting time series proved to be unconvincing, reflecting the difficulty in separately identifying the extent of product cycles and their affects as opposed to the impact the Depression. A marked peak in productivity was estimated immediately prior to 1929. Productivity plummeted during the Depression, thereafter, there was a mild recovery, but essentially productivity remained flat and well below the prior peak.
} 
Our measures of potential productivity and work intensity are constructed using the trends-through-peaks methodology suggested in Fair (1985). These series are illustrated in Figure 1, with actual and potential productivity shown in the upper graphs and work intensity in the lower graphs ${ }^{10}$. In estimation, we do not use data beyond 1939 so as to avoid the impact of WWII on measured productivity. The calculated trends represent potential productivity $\left(\phi^{*}\right)$ and are based on logged series, so productivity grows at a constant rate between successive peaks.

The Paper and Pulp and Textile industries display downward spikes in measured productivity and work intensity that best fit with a priori expectations. These occur quite markedly at the time of the Depression and, again, at the recession that began in 1937. Leather is quite similar although in this case the Depression impact appears to have been delayed by one year. Steel also shows a delayed response though in this case the influence of the Depression is less clearly differentiated from other periods of productivity downswings. The Depression is clearly the major period of productivity decline in Petrol. By contrast, productivity movements in Lumber and Rubber do not appear to be unduly influenced by the early Depression ${ }^{11}$, although Rubber does show a downward productivity movement in 1937.

\footnotetext{
${ }^{10}$ In practice, two key alternatives are also widely used. The first is detrending through the application of simple filters (e.g. Hodrick Prescott). In the present context, this would focus on obtaining "average" rather than peak work intensity and, for our purposes, they give too much influence to the below-peak data points. The second is to use a stochastic frontier approach that explicitly attempts to fit the outer envelope of the curve. In practice, this would require us to estimate a behavioural equation determining peak productivity and unfortunately the available data precludes this level of detail.

11 While Bernstein (1987) does report short-run downturns in product demand in these two industries during the early 1930s, secular influences were clearly very strong. A slow growth in the housing market, due to immigration restrictions, together with a low rate of population growth were clearly important factors in Lumber. Also, there was a growing substitution of metal products for timber used in construction. (see Fabricant (1940)). In Rubber, the continual improvement in tyres, mounting foreign competition, and a slow development in alternative uses for the product combined to shrink the market.
} 
Figure 1: Actual and Potential Productivity and Work Intensity in Seven Manufacturing Industries, 1921-1942

LEATHER
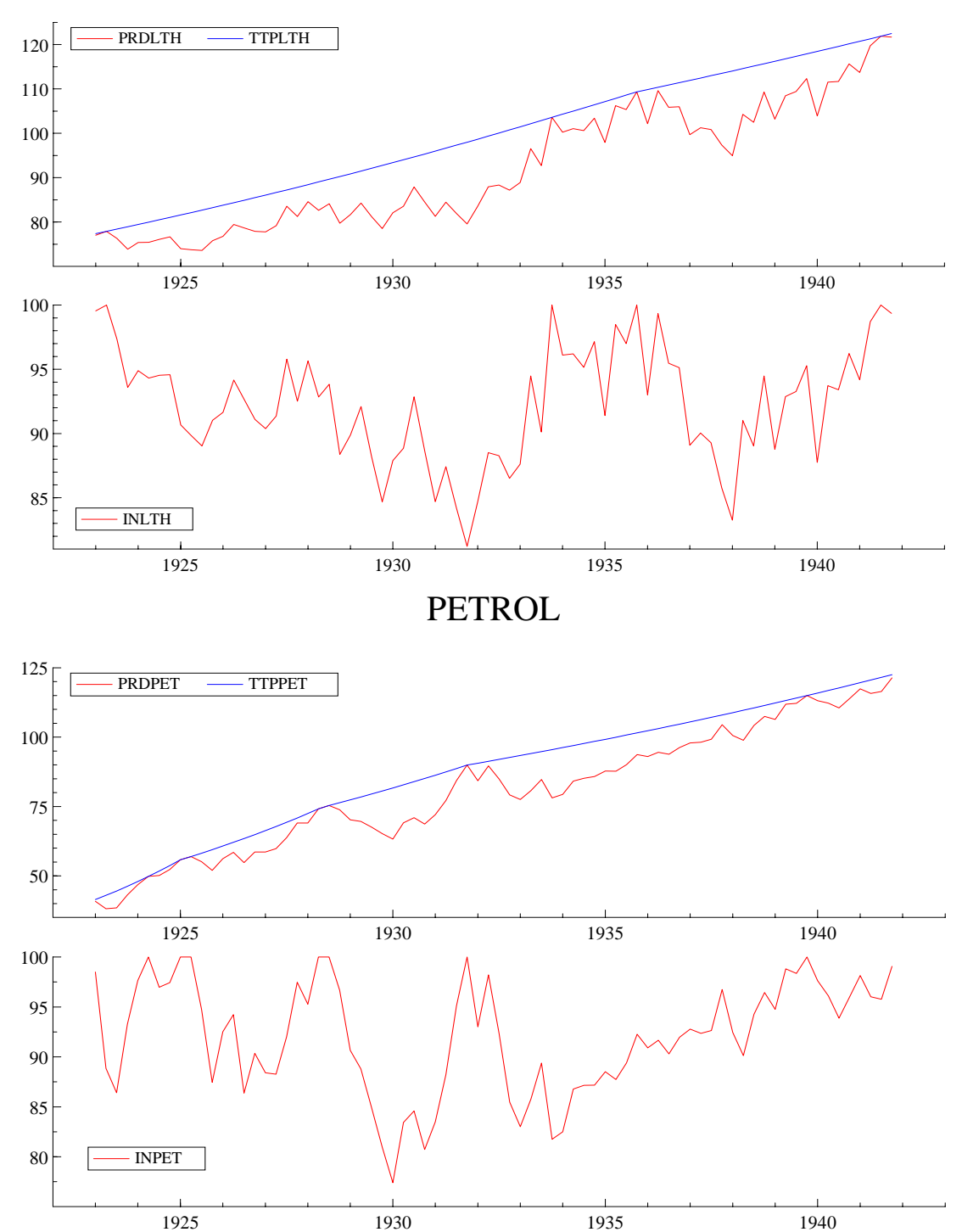

LUMBER
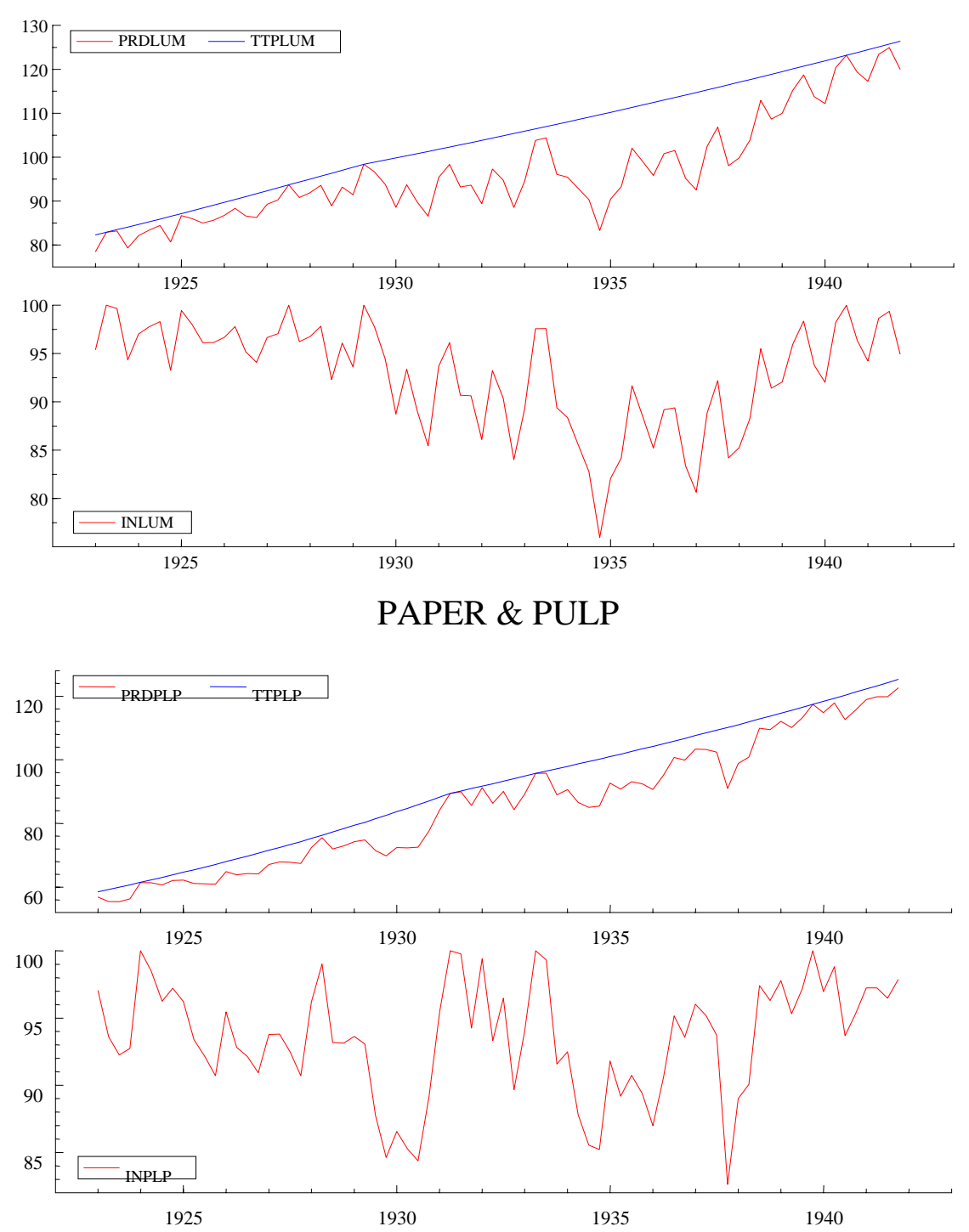
Figure 1 [continued...]

\section{RUBBER}
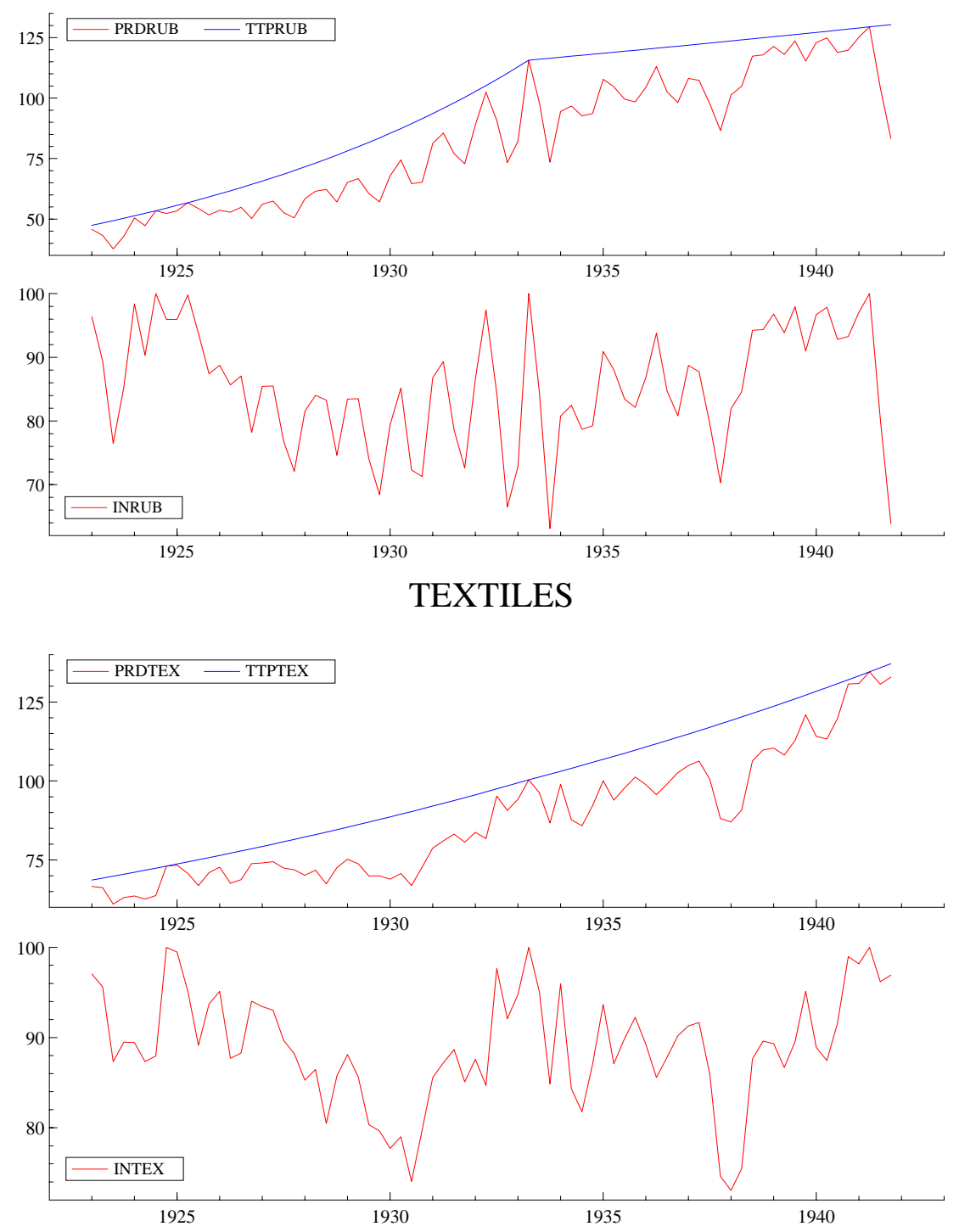

STEEL
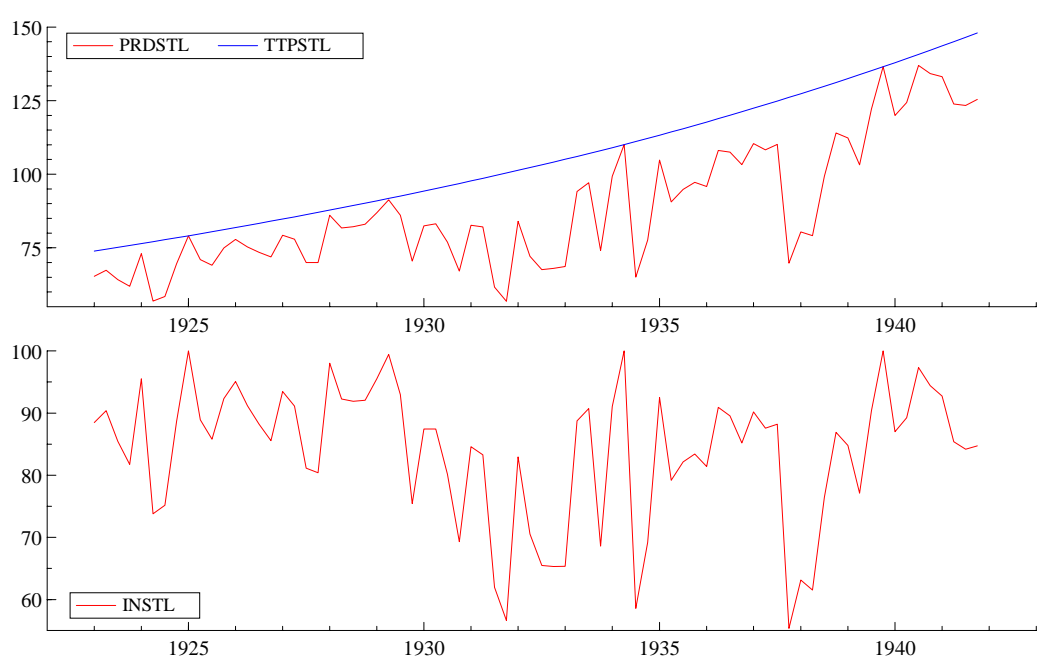


\section{Estimation and Results}

Estimation of equation (14) is by three stage least squares, involving simultaneous estimation of all the industry wage equations augmented by industry specific equations for work intensity and for whole economy consumer price inflation. This approach ensures that the wage equations treat the change in work intensity and consumer price inflation as endogenously determined. The instrumenting regressions for the change in work intensity include lagged work intensity, industry specific producer price inflation, lagged changes in hours worked and unemployment, while instruments for consumer price inflation include terms in lagged inflation and unemployment, their explanatory power is confirmed by significant equation F tests. Instrumental variables estimation of each industry’s wage equation would be consistent but three stage least squares estimation has the added advantage of improving the efficiency of estimation given cross equation correlations in the residuals which are highly likely in the presence of common shocks across all industries. The relative advantage of three stage least squares increases with the strength of the interrelations among the error terms (Besley, 1988). We would expect that the Great Depression is one of the most dramatic common shocks imaginable and a reduction in the virtually all the coefficients standard errors are evident when comparing the three stage least squares and instrumental variables estimates. Finally a Hausman test comparing SUR estimates of the full system with three stage least squares again confirm the superiority of our three stage least squares estimates $^{12}$.

\footnotetext{
${ }^{12}$ A Hausman test was used to compare 3SLS and SUR estimates of the industry wage equations. Under the null hypothesis for this test is that SUR is efficient, while 3SLS is consistent under both the null and alternative. The test checks for systematic differences in the estimates. We are easily able to reject the null hypothesis that the difference between the estimates is not systematic (the relevant test statistic is 201.9 and is distributed as $\chi^{2}$ (83)and the probability value for the test is .00). We conclude that SUR is inconsistent and 3SLS is the preferred estimator..
} 
Table 1: Estimated Wage Equations

The dependent variable is the change in the log of the nominal wage, $\Delta \ln (W / P)_{t}$, data are quarterly and the sample period is 1924:1-1939:4. Estimation is by three stage least squares and standard errors are given in parenthesis.

\begin{tabular}{|c|c|c|c|c|c|c|c|}
\hline & Leather & Lumber & Petrol & Pulp & Rubber & Steel & Textiles \\
\hline $\ln (W / P)_{t-1}$ & $\begin{array}{l}-0.453 \\
(0.073)\end{array}$ & $\begin{array}{l}-0.262 \\
(0.057)\end{array}$ & $\begin{array}{l}-0.173 \\
(0.033)\end{array}$ & $\begin{array}{l}-0.179 \\
(0.026)\end{array}$ & $\begin{array}{l}-0.135 \\
(0.047)\end{array}$ & $\begin{array}{l}-0.264 \\
(0.055)\end{array}$ & $\begin{array}{l}-0.406 \\
(0.036)\end{array}$ \\
\hline $\ln \phi^{*}{ }_{t}$ & $\begin{array}{c}0.332 \\
(0.083)\end{array}$ & $\begin{array}{c}0.242 \\
(0.080)\end{array}$ & $\begin{array}{c}0.106 \\
(0.028)\end{array}$ & $\begin{array}{c}0.103 \\
(0.020)\end{array}$ & $\begin{array}{c}0.044 \\
(0.025)\end{array}$ & $\begin{array}{c}0.277 \\
(0.076)\end{array}$ & $\begin{array}{c}0.193 \\
(0.035)\end{array}$ \\
\hline$\Delta \ln W_{t-1}$ & $\begin{array}{c}0.201 \\
(0.073)\end{array}$ & & & & $\begin{array}{l}-0.386 \\
(0.095)\end{array}$ & $\begin{array}{c}0.221 \\
(0.064)\end{array}$ & $\begin{array}{c}0.335 \\
(0.050)\end{array}$ \\
\hline$\Delta \ln \mathrm{W}_{\mathrm{t}-2}$ & & & & $\begin{array}{c}0.353 \\
(0.055)\end{array}$ & & $\begin{array}{c}0.131 \\
(0.065)\end{array}$ & \\
\hline$\Delta \ln P_{t}$ & & & & $\begin{array}{c}0.869 \\
(0.105)\end{array}$ & $\begin{array}{c}0.605 \\
(0.211)\end{array}$ & & $\begin{array}{c}1.059 \\
(0.141)\end{array}$ \\
\hline$\Delta \ln P_{t-1}$ & $\begin{array}{c}1.195 \\
(0.271)\end{array}$ & $\begin{array}{c}0.726 \\
(0.235)\end{array}$ & & & & $\begin{array}{c}0.680 \\
(0.241)\end{array}$ & $\begin{array}{c}0.858 \\
(0.180)\end{array}$ \\
\hline$\Delta \ln \theta_{\mathrm{t}}$ & $\begin{array}{c}0.423 \\
(0.074)\end{array}$ & $\begin{array}{c}0.190 \\
(0.059)\end{array}$ & $\begin{array}{c}0.263 \\
(0.050)\end{array}$ & $\begin{array}{c}0.227 \\
(0.036)\end{array}$ & & & $\begin{array}{c}0.161 \\
(0.032)\end{array}$ \\
\hline$\Delta \ln \theta_{\mathrm{t}-2}$ & & & & $\begin{array}{c}0.103 \\
(0.035)\end{array}$ & & & $\begin{array}{c}0.095 \\
(0.029)\end{array}$ \\
\hline $\ln \theta_{\mathrm{t}-2}$ & & $\begin{array}{c}0.319 \\
(0.059)\end{array}$ & & & & & \\
\hline$\Delta \ln \mathrm{u}_{\mathrm{t}-2}$ & & & & & & $\begin{array}{l}-0.183 \\
(0.035)\end{array}$ & $\begin{array}{l}-0.037 \\
(0.010)\end{array}$ \\
\hline $\ln u_{t-1}$ & $\begin{array}{l}-0.065 \\
(0.015)\end{array}$ & & & & & & \\
\hline $\ln r_{t}$ & $\begin{array}{c}0.023 \\
(0.005)\end{array}$ & & & & & & $\begin{array}{c}0.018 \\
(0.003)\end{array}$ \\
\hline Strike $_{t}$ & $\begin{array}{l}-0.108 \\
(0.048)\end{array}$ & $\begin{array}{c}0.112 \\
(0.041)\end{array}$ & $\begin{array}{c}0.146 \\
(0.028)\end{array}$ & $\begin{array}{c}0.068 \\
(0.020)\end{array}$ & $\begin{array}{c}0.144 \\
(0.041)\end{array}$ & $\begin{array}{c}0.114 \\
(0.048)\end{array}$ & $\begin{array}{l}-0.058 \\
(0.032)\end{array}$ \\
\hline $\mathrm{NRA}_{t}$ & $\begin{array}{c}0.023 \\
(0.005)\end{array}$ & $\begin{array}{c}0.020 \\
(0.012)\end{array}$ & $\begin{array}{c}0.026 \\
(0.008)\end{array}$ & $\begin{array}{c}0.018 \\
(0.013)\end{array}$ & $\begin{array}{c}0.048 \\
(0.012)\end{array}$ & $\begin{array}{c}0.021 \\
(0.013)\end{array}$ & $\begin{array}{c}0.041 \\
(0.010)\end{array}$ \\
\hline "R-Squared" & 0.714 & 0.764 & 0.624 & 0.829 & 0.485 & 0.787 & 0.857 \\
\hline \multicolumn{8}{|l|}{$\begin{array}{l}\text { Serial } \\
\text { Correlation: }\end{array}$} \\
\hline$L M(1)$ & $2.20[.14]$ & $1.92[.17]$ & $0.76[.39]$ & $0.26[.61]$ & $0.73[.39]$ & $0.06[.81]$ & $0.11[.74]$ \\
\hline LM(3) & $4.24[.24]$ & $3.29[.36]$ & $1.35[.72]$ & $0.94[.81]$ & $2.20[.53]$ & $0.01[.99]$ & $1.68[.64]$ \\
\hline
\end{tabular}

Variable definitions: $W / P=$ real average hourly wage, $W=$ average nominal hourly wage, $P=$ consumer price index, $\phi^{*}$ = potential productivity, $\theta=$ work intensity, $u=$ unemployment rate, $r=$ relative wage of emergency workers, Strike = thousands of man days lost through strikes, $N R A=$ national recovery act dummy. Information on data sources is provided in an appendix. Estimation was conducted using Stata. "R-Squared" is the pseudo Rsquared reported by Stata. The tests for Serial Correlation are LM tests from auxiliary regressions, p-values are reported in brackets. 
Estimates of equation (14) are shown in Table 1. While we apply a common model to all seven industries, our approach is sufficiently versatile to enable us to identify some interesting differences in wage responsiveness across industries. The reported equations are the result of application of a general-to-specific methodology (see, for example, Hendry 1994). The general specifications for each industry incorporated sufficient lags of the differenced terms so as to be consistent with an absence of significant serial correlation. These specifications constitute a benchmark against which parsimonious representations were tested. The table reports the final wage equations for each industry.

The first row of coefficients in the table pin down the adjustment in the level of the real wage, ensuring that wages and prices to move one for one in the long run. The size of the real wage coefficient determines the speed of adjustment (the coefficient has to lie between 0 and -1 , and the closer to -1 the faster the adjustment). It is important to note that the coefficient is significantly different from zero in every case,as this provides a check on the validity of the theoretical specification.

There are two major areas of interest in the results.

\section{(i) Potential productivity and competition}

The estimates in Table l indicate that potential productivity has a strongly significant positive influence on wages in all seven industries. It is useful to compare the coefficient on lagged potential productivity (row 2) with that on the lagged real wage (row 1). Where these coefficients are equal in size and opposite in sign, the implication is that a given increase in potential productivity will, in the long-run, lead to the same increase in real wages, ceteris paribus. The summary table below reports freely estimated long-run coefficients on potential productivity. In the case of Steel, the freely estimated coefficients imply that wage growth outpaces potential productivity growth in the long run. However, upon testing, we cannot reject the null hypothesis of a unit long run coefficient. Furthermore imposing this data 
admissible restriction has very little impact on the remaining coefficients, all our key conclusions continue to hold.

Table 2 - The estimated long run impact of potential productivity on real wages

\begin{tabular}{lccccccc}
\hline & Leather & Lumber & Petrol & Pulp & Rubber & Steel & Textiles \\
\hline LR & 0.73 & 0.92 & 0.61 & 0.58 & 0.33 & 1.05 & 0.48 \\
t-test of $\mathrm{H}_{0}$ & $1.7[.08]$ & $0.4[.67]$ & $4.0[.00]$ & $5.0[.00]$ & $2.8[.01]$ & $0.4[.72]$ & $5.9[.00]$ \\
$\begin{array}{l}\text { LR coef }=1 \\
\text { [p-value] }\end{array}$ & & & & & & & \\
\hline
\end{tabular}

In the remaining industries our estimates suggest that wage growth fell behind that of potential productivity. This is particularly clear in the rubber industry, which benefited from large productivity gains during our sample period. Nelson (1988) points out that these gains were achieved largely as a result of the introduction of automated tyre cutting. However, the consequent increased durability of tyres was combined with depressed demand from a weakened Autos industry. (In general, the Depression had a greater impact on demand for durable goods such as Autos.) In addition, the late 1920s and early 1930s marked a significant increase in foreign competition in this industry, particularly from Malaysia. These factors would have acted to moderate wage growth even in the face of substantial advances in potential productivity. Competitive pressures also impacted on Textiles manufacturers, as discussed in Davis et al. (1972). They note that fierce competition from expanding textile mills in Southern states had been a key factor in driving down prices and remuneration in the older established mills, well before the Depression years. In the 1930s the industry faced “fundamental alterations... not only in the sector's geographical location within the United States and around the world but also the industry’s role within American manufacturing" (Bernstein, 1987). 
(ii) Internal and external measures of excess labor supply

Work intensity is measured as the gap between actual and potential hours' efficiency. Changes in potential productivity only occur slowly over time, so reductions in work intensity tend to be caused by a drop in product demand that is not matched by a full adjustment in the stock of employment. Contemporaneous changes in work intensity have a significant impact on wage adjustments in five of the seven industries. The level of work intensity enters significantly in the Lumber equation ${ }^{13}$.

Only in the Rubber and Steel industries do we fail to identify any significant impact from work intensity. In each of these industries other authors have pointed to evidence that firms responded to falling demand for their products in ways that left workers achieving their productive ‘norms' over a shorter working week. The rubber industry was dominated by tyre manufacture and Nelson (1988) points out that the industry- rather than firm- specific nature of human capital had led to high labor turnover. A common response was for firms to provide career employment plans, company sponsored housing and social centers etc. A 6-hour day was introduced as a way of retaining employees in key positions. "While the six hour day was an ad hoc response to the depression, it was consistent with...[Goodyear's] larger goals...[One of which] as to maintain a cadre of experienced employees...[in order to] take maximum advantage of the revival, as...in 1922" (Nelson, 1988, p. 114). This reduction in working time may well have served significantly to offset the need to reduce the degree of work intensity. In the Steel industry too there is evidence that firms found it efficient to operate on a part-time basis, working their employees a few days of the week on 'spreadwork' schedules (see Bernanke, 1986, p.89 and Daugherty et al., 1937, p.165). Note that this

\footnotetext{
13 This may owe something to the marked secular decline in these industries which predated the Great Depression. The decline in lumber reflected a shift in demand away from wood and toward concrete and steel for use in construction. In contrast to say the pulp industry, the lumber industry did not diversify into new products until the war.
} 
might have enabled firms to pay constant or rising real hourly wages although, as emphasised by Bernanke, weekly earnings were bound to suffer.

By contrast, the exisiting literature reveals a number of other industries were remarkably adaptable. For example, in the Paper and Pulp although output fell and bankruptcy was rife, there is evidence that the surviving producers became adept at developing new products ${ }^{14}$ and anticipating market changes (Bernstein, 1987, p85.). These changes addressed head on the need to eliminate under utilization and to restore potential productivity. Both effects come through strongly in the results in Table 1.

Unemployment, our measure of external excess labor supply, is a significant determinant of wages in only three industries, Leather, Textiles and and Steel, and it's notable that the effect is delayed, and relatively small. The replacement ratio, $r$, only has a significant impact in the Leather and Textiles equations.

\section{Concluding comments}

In line with other studies, we find a weak association between real wages and unemployment within U.S. industries during the Great Depression. While real wages were not significantly associated with this extensive margin measure of excess labor supply, we do obtain much stronger support for an influence from its intensive margin equivalent - i.e. an excess of total paid-for hours relative to effective actual hours worked. Since this internal excess hours supply grew considerably during the Great Depression we argue that the associated reduction in work intensity would have been expected to impact directly on the real wage. In the long-term, potential productivity is found to have a comprehensively strong positive effect on real wages. Where work intensity falls below levels associated with meeting potential productivity then, for most of our industries, there is a significant negative

\footnotetext{
${ }^{14}$ The creation of new product lines included paperboard containers (which were increasingly substituted for wooden products), cheaper grades of writing paper, paper towels, tissues and various medical products.
} 
impact on real wage growth. The change in work intensity, as opposed to its level, is found to play the major role.

Without a doubt, improved measurement and data refinements may well serve to modify our findings. First, the productivity-based trends-through-peaks method of proxying work intensity is something of a blunt instrument in that it does not allow us to discriminate between traditional labor market explanations of changes in work intensity and other factors that may have affected productive performance. Ohanian (2002) tells us that obvious work intensity related variables, like changes in capacity utilization and labor hoarding, possibly accounted for only about one-third of the decline in total factor productivity at this time. In fact, Ohanian suggests decreases in organization capital - 'the knowledge firms use to organize production' - as an additional factor behind the observed productivity decreases. Unfortunately, in practice our measure of work intensity may be influenced by the adverse effects of the Depression on firms’ organizational efficiency in respect of production and inventory scheduling, supplier relationships, and marketing strategies, but it is likely to be difficult if not impossible to model all these factors simultaneously, so we are forced simply to note this potential weakness. Second, and perhaps more importantly, the use of more micro-level data might well reveal composition biases that lead us to revise upward the significance of the role the external market played in the wage determination process at this time. If the industry-level data hide the fact that low-skilled workers showed higher propensities to (a) lose their jobs in the early 1930s and (b) be hired during the later recovery phase, then our unemployment effects will almost certainly be underestimating the true procyclicality of real wages (see Solon et al., 1994). 


\section{Data Appendix}

\section{Definition}

W/P real wage $=$ nominal wage $/ \mathrm{CPI}$

$W \quad$ nominal wage = average hourly earnings, constructed as pay/(emp.ahw) converted into an index, $1937=100$

pay = payroll, by industry

emp = total employment, by industry

ahw $=$ average hours worked, by industry

$P \quad$ consumer price index, CPI

$\phi \quad$ productivity= iip/(emp.ahw);

iip = index of industrial production

$\phi^{*} \quad$ Potential productivity defined as trend through peaks

$\theta \quad$ work intensity $=\phi \div \phi^{*}$

$\mathrm{u} \quad$ unemployment rate

$r \quad$ Replacement rate $=$ relative wage of an emergency worker, funded through various New Deal programmes.

Strike Takes the value 0 up to 1935 , then is equal to the thousands of man-days idled by strikes in the US economy as a whole (this includes strikes beginning in the quarter as well as those still in progress from a previous quarter). Industry specific data is not available.

NRA A dummy variable intended to capture any wage impact of the National Recovery Act and is set to 1 from 1933:4 - 1935:2 and to zero otherwise.

\section{Source}

Constructed

construct using date provided by Bernanke and Parkinson (BP), original sources National Industiral Conference Board (NICB) and Bureau of Labour Statistics (BLS)

BP, BLS

constructed

BP, Federal Reserve Bulletin.

constructed (see Figure 1)

constructed

NBER

Darby (1976)

BP, BLS Bulletins

constructed as per Bernanke (1986) 


\section{References}

Bernstein, M A. 1987. The Great Depression: delayed recovery and economic change in America, 1929-1939. Cambridge: Cambridge University Press.

Bernanke, B S. 1986. Employment, hours, and earnings in the Depression: an analysis of eight manufacturing industries. American Economic Review 76, 82-109.

Bernanke, B S and M L Parkinson. 1991. Procyclical labor productivity and competing theories of the business cycle: some evidence from interwar U.S. manufacturing industries. Journal of Political Economy 99, 439-459

Bernanke, B S and J Powell. 1986. The cyclical behavior of industrial labor markets: a comparison of pre-war and post-war eras. In R. J. Gordon, ed., The American business cycle: continuity and change, Chicago, University of Chicago Press.

Besley, D.A. 1988. Two- or three-stage least squares? Computational Economics 1, 21-30.

Cole, H L and L E Ohanian. 1999. The Great Depression in the United States from a neoclassical perspective. Federal Reserve Bank of Minneapolis Quarterly Review 23, $2-24$.

Darby, J, R A Hart and M Vecchi. 2001. Wages, work intensity and unemployment in Japan, UK and USA. Labour Economics 8, 243-258.

Darby, M R. 1976. Three-and-a-half million U.S. employees have been mislaid: or, an explanation of unemployment, 1934-1941. Journal of Political Economy 84, 1-16.

Daugherty, C.R., M.de Chazeau and S.S.Stratton. 1937. The Economics of the Iron and Steel Industry. Pittsburgh:Bureau of Business Research, Volumes I and II.

Davis L.E., R.E.Easterlin and W.N.Parker (eds.), 1972, American Economic Growth: An Economist's History of the United States Harper Row, New York.

Fabricant, S., 1940, The Output of Manufacturing Industries, 1899-1937, NBER New York.

Fair, R C. 1985. Excess labor and the business cycle. American Economic Review 75, 239245.

Hart, R. A. 2001. "Hours and wages in the Depression: British engineering, 1926-1938", Explorations in Economic History 38, 478-502.

Hart R A and T Moutos. 1995. Human capital, employment and bargaining. Cambridge, Cambridge University Press. 
Hendry, D F. 1994. Dynamic Econometrics. Oxford, Oxford University Press.

Johnson, G. 1990. Work rules, featherbedding, and Pareto-optimal union-management bargaining. Journal of Labor Economics 8, S237 - S259.

Nelson, D. 1988. American rubber workers and organized labor, 1900-1941. Princeton, Princeton University Press.

Ohanian, L.E. 2002. Why did productivity fall so much during the Great Depression? Federal Reserve Bank of Minneapolis Quarterly Review 26(2), 12-17.

Solon, G., R. Barsky, J.A. Parker. 1994. Measuring the cyclicality of real wages: how important is composition bias?. Quarterly Journal of Economics 109, 1 - 25.

Svejnar, J. 1986. Bargaining power, fear of disagreement, and wage settlements: theory and evidence from U.S. industry. Econometrica 54, 1055-78.

Taylor J. 1970. Hidden unemployment, hoarded labor, and the Phillips curve. Southern Economic Journal 37, 1-16. 